\title{
Evaluation of the Use of Short Acting Insulin in the Management of Mild to Moderate Diabetic Ketoacidosis: A Simple Literature Review
} Ali Abdullah Alnajrani ${ }^{1}$, Suhaib Abdulrahman Al-Khilaifi ${ }^{2}$, Sultan Salman Aldhafeeri ${ }^{3}$, Nasser Falah Alqahtani ${ }^{4}$, Reem Ahmed B. Alanazi ${ }^{4}$, Rawan Adel Shafaay ${ }^{4}$, Sufana Mohamedwageeh Saadi $^{5}$, Aishah Abdulrahman Al-Hamoud ${ }^{6}$, Hadeel Salem Alwagdani ${ }^{7}$, Naseem Ahmad Matari ${ }^{8}$

${ }^{1}$ Najran University, ${ }^{2}$ Umm Al-Qura University, ${ }^{3}$ Qassim University, ${ }^{4}$ Almaarefa College, ${ }^{5} \mathrm{Ibn}$ Sina National College, ${ }^{6}$ King Faisal University, ${ }^{7}$ Taif University, ${ }^{8}$ King Khalid University

\begin{abstract}
Background: Diabetes mellitus (DM) is one of the most common chronic diseases. It can cause a lot of complications such as retinopathy, nephropathy, and neuropathy. Patients with DM are at risk of having acute attacks of hyperglycemia and ketoacidosis as well as hypoglycemia. Diabetic ketoacidosis management is accomplished by the administration of intravenous infusion of regular insulin. Intravenous insulin infusion requires ICU admission in most of institutions, which will increase the hospitals cost (infusion pumps, IV access, nurses). Accordingly, we have done a literature study to determine whether intermittent subcutaneous use of these rapid-acting analogs might be as effective as intravenous insulin infusions in treating uncomplicated diabetic ketoacidosis.

Objective: In this study, we aimed at evaluating the effect of using short acting insulin in the management of mild to moderate DKA.

Methods: PubMed database was used for articles selection, and the following keys were used in the mesh ("Insulin Lispro"[Mesh]) AND ("Diabetic Ketoacidosis/drug therapy"[Mesh] OR "Diabetic Ketoacidosis/therapy"[Mesh]) A total of 13 articles were found, with further restriction by PubMed filters, and reviewing the articles titles and abstracts the final results were 5 articles.

Conclusion: Subcutaneous (S/C) Aspart insulin every 2 hours can be as safe and effective as SC Lispro insulin every one hour and as continuous IV insulin infusion in the treatment of mild to moderate uncomplicated cases of DKA. There was no significant statistical difference among the 3 approaches regarding the efficacy, and the mean duration of the treatment period. SC aspart insulin every 2 hours is more economical and fairer type intervention.
\end{abstract}

Keywords: Short acting insulin, diabetic ketoacidosis, evaluation, subcutaneous aspart insulin.

\section{INTRODUCTION}

Diabetes mellitus is a complex metabolic disorder whose main clinical and diagnostic feature is hyperglycemia ${ }^{(1)}$. Diabetes has reached epidemic proportions, affecting around 387 million people worldwide. Over the next 20 years, its prevalence is predicted to double, and more than half-a billion people will be affected ${ }^{(2)}$. Estimated regional diabetes prevalence ranges from $5.1 \%$ in Africa to $11.4 \%$ in North America and the Caribbean, with more than $75 \%$ of subjects living in low and middle-income countries ${ }^{(2)}$. Moreover, the increase in prevalence is estimated to be greater in developing areas ${ }^{(3)}$, as many countries adopt Western life style habits (sedentary behavior, lack of physical activity and energy-dense diet) which are well recognized risk factors for type 2 diabetes mellitus (T2DM) ${ }^{(4)}$.

Diabetes mellitus, second only to hypertension as the most common chronic condition of emergency department (ED) patients, can cause acute hyperglycemia and ketoacidosis, responsible for more than 1 million ED visits in $2005{ }^{\text {(5) }}$. Traditionally (and more recently endorsed by the American Diabetes Association) ${ }^{(6)}$, the treatment of diabetic ketoacidosis is accomplished by the administration of a low dose intravenous infusion of regular insulin that is initiated in the $\mathrm{ED}$ and continued in an ICU 7 setting for frequent insulin/ fluid adjustments, glucose monitoring, and electrolyte assessment. Although insulin administration by any route is effective for treating diabetic ketoacidosis, intravenous insulin is preferred over subcutaneous and intramuscular insulin because it provides rapid, titratable glycemic control ${ }^{(7,8)}$.

Intravenous insulin infusion requires ICU admission in most of institutions, which will increase the hospitals cost (infusion pumps, IV access, nurses) Therefore, in the present study, it was aimed at determining whether intermittent subcutaneous use of these rapid-acting analogs might be as effective as intravenous insulin infusions in treating uncomplicated diabetic ketoacidosis.

\section{METHODOLOGY}

\section{Sample}

PubMed was chosen as the search database for the articles selection, because it is one of the major research databases within the suite of resources that have been developed by the National Center for Biotechnology Information (NCBI). The following keys were used for the Mesh ("Insulin Lispro"[Mesh]) AND ("Diabetic Ketoacidosis/drug therapy"[Mesh] OR "Diabetic Ketoacidosis/ 
therapy"[Mesh]). A total of 13 articles were found, with further restriction by PubMed filters, and reviewing the articles titles and abstracts the final results were 5 articles. In regards to the Inclusion criteria, the articles were selected based on the relevance to the project which should include one of the following topics, \{Diabetic Ketoacidosis, Rapid Acting Insulin, Insulin Lispro\}. Exclusion criteria were all other articles which did not have one of these topics as their primary end point, or repeated studies, and systematic reviews or metaanalysis.

\section{Analysis}

No software was used to analyze the data. The extracted data were based on specific form that contain (Title of the study, name of the author, Objective, Summary, Results, and Outcomes) These data were reviewed by the group members. Double revision of each member's outcomes was applied to ensure the validity and minimize the mistakes.

\section{RESULTS}

Umpierrez et al $^{(9)}$ Compared the efficacy and safety of aspart insulin given subcutaneously at different time intervals to a standard low-dose intravenous (IV) infusion protocol of regular insulin in patients with uncomplicated diabetic ketoacidosis (DKA). This is a controlled clinical trial done in 2004 at the University of Tennessee Regional Medical Center, Memphis. They carried out their study on a total number of 45 patients who were diagnosed in the Emergency department with DKA. Patients were randomly assigned in the emergency department to receive $\mathrm{SC}$ aspart insulin every hour $(\mathrm{SC}-1 \mathrm{~h}, \mathrm{n}=15)$ or every $2 \mathrm{~h}(\mathrm{SC}-2 \mathrm{~h}$, $n=15)$, or to receive IV regular insulin $(n=15)$. Then, they assessed the effect of the different therapies on the patients using multiple parameters until resolution of hyperglycemia and ketoacidosis.

They found that admission biochemical parameters in patients treated with SC-1h were similar to those treated with SC-2h and IV regular insulin. There were no statistical difference in the mean duration of treatment until correction of hyperglycemia or until resolution of ketoacidosis among patients treated with SC-1h and SC-2h or with IV insulin, respectively. In addition, there was no mortality and no difference in the length of hospital stay, total amount of insulin administration until resolution of hyperglycemia or ketoacidosis, or the number of hypoglycemic events among treatment groups.

Conclusively, their results indicated that the use of subcutaneous insulin aspart every 1 or 2 $\mathrm{h}$ represents a safe and effective alternative mean to be used for intravenous regular insulin in the management of patients with uncomplicated DKA.

Manna et al. ${ }^{(10)}$ compared the efficacy of a subcutaneous fast-acting analog (lispro) with continuous intravenous regular insulin (CIRI) in the treatment of pediatric DKA. This was a controlled clinical trial done during 2 years period from 2001 to 2003 in Sao Paulo University Children's Hospital. They studied 60 DKA occurrences in children admitted to the Emergency department. Of the 60 DKA episodes, 30 were randomized to treatment with a subcutaneous fast-acting insulin analog (lispro) and the other 30 were randomized to treatment with CIRI. Then, the patients were monitored clinically and regarding their laboratory tests. They found that capillary glucose levels decreased by 2.9 and 2.6 mmol in the lispro and CIRI groups, respectively, but blood glucose fluctuated at different time intervals. In the CIRI group, metabolic acidosis and ketosis resolved in the first 6-h period after capillary glucose reached $13.8 \mathrm{mmol} / \mathrm{l}$, whereas in the lispro group, they resolved in the next 6-h interval; however, both groups met DKA recovery criteria without complications. Therefore, DKA treatment with a subcutaneous fast-acting insulin analog represents a cost-effective and technically simplified procedure that precludes intensive care unit admission.

Ersoz et $\boldsymbol{a l l}^{\left({ }^{(11)}\right.}$ evaluated the efficacy and safety of hourly SC insulin lispro administration in the treatment of DKA in comparison with standard IV regular insulin treatment. This was a prospective randomized open trial done in 2006 in Trabzon, Turkey. The study included 20 DKA patients and assigned them into two groups. Following a bolus injection of $0.15 \mathrm{U} / \mathrm{kg}$ IV regular insulin, group L received half of this dose as hourly $\mathrm{SC}$ insulin lispro, while group $\mathrm{R}$ was treated conventionally with standard IV regular insulin infusion. At the end of treatment period, time that needed for normalization of serum glucose, bhydroxybutyrate, blood $\mathrm{pH}$ and urine ketone levels were not different in groups $\mathrm{L}$ and $\mathrm{R}$. There was no mortality or serious side effects in both groups. So, treatment of mild and moderate DKA with SC 
insulin lispro is equally effective and safe in comparison with IV regular insulin.

Umpierrez et al. $^{(12)}$ compared the efficacy and safety of subcutaneous insulin lispro with that of low-dose continuous intravenous regular insulin in the treatment of patients with uncomplicated diabetic ketoacidosis. This was a prospective randomized open trial done in 2004. The study assigned 40 patients with diabetic ketoacidosis who were recruited from the Atlanta Medical Center and the University of Tennessee Health Science Center. Patients were randomized into groups according to the intervention. 20 patients, treated with subcutaneous insulin lispro, were managed in regular medicine wards $(\mathrm{n}=10)$ or an intermediate care unit $(n=10)$, while 20 patients, treated with the intravenous protocol, were managed in the intensive care unit. Then, multiple parameters were analyzed and used to compare among the outcomes of the groups' conditions.

The study resulted in that Mean $( \pm$ SD) admission biochemical parameters in patients treated with subcutaneous lispro was similar to values in patients treated with intravenous insulin. The duration of treatment until correction of hyperglycemia and resolution of ketoacidosis in patients treated with subcutaneous lispro was not different compared to patients treated with intravenous regular insulin. They concluded that treatment of adult patients who have uncomplicated diabetic ketoacidosis with subcutaneous lispro every hour in a non-intensive care setting may be safe and more cost-effective than treatment with intravenous regular insulin in the intensive care unit.

Table (1): Included studies details.

\begin{tabular}{|c|c|c|c|c|c|c|c|}
\hline $\begin{array}{l}\text { Study } \\
\text { (Year) }\end{array}$ & $\begin{array}{l}\text { Study } \\
\text { Design }\end{array}$ & Country & $\begin{array}{c}\text { Number of } \\
\text { participants }\end{array}$ & Objective & $\begin{array}{c}\text { Duration } \\
\text { of Study }\end{array}$ & Outcome & Ref. \\
\hline $\begin{array}{l}\text { Umpierrez } \\
\text { et al. }\end{array}$ & RCT & USA & 45 & $\begin{array}{l}\text { to compare the use of } \\
\text { aspart insulin, given at } \\
\text { different time intervals } \\
(1 \text { and } 2 \mathrm{~h}) \text {, with a } \\
\text { standard IV low-dose } \\
\text { insulin protocol }\end{array}$ & & $\begin{array}{l}\text { the use of subcutaneous } \\
\text { insulin aspart every } 1 \text { or } 2 \\
\mathrm{~h} \text { represents a safe and } \\
\text { effective alternative to the } \\
\text { use of intravenous regular } \\
\text { insulin in the management } \\
\text { of patients with } \\
\text { uncomplicated DKA }\end{array}$ & 9 \\
\hline $\begin{array}{l}\text { Manna et } \\
\text { al. }\end{array}$ & RCT & Brazil & 60 & $\begin{array}{l}\text { to compare the efficacy } \\
\text { of a subcutaneous fast- } \\
\text { acting analog (lispro) } \\
\text { with continuous } \\
\text { intravenous regular } \\
\text { insulin (CIRI) in the } \\
\text { treatment of pediatric } \\
\text { DKA } \\
\end{array}$ & 2 years & $\begin{array}{c}\text { DKA treatment with a } \\
\text { subcutaneous fast-acting } \\
\text { insulin analog represents a } \\
\text { cost-effective and } \\
\text { technically simplified } \\
\text { procedure that precludes } \\
\text { intensive care unit } \\
\text { admission } \\
\end{array}$ & 10 \\
\hline Ersoz et al. & RCT & Turkey & 20 & $\begin{array}{c}\text { to evaluate the efficacy } \\
\text { and safety of hourly SC } \\
\text { insulin lispro } \\
\text { administration in the } \\
\text { treatment of DKA in } \\
\text { comparison with } \\
\text { standard IV regular } \\
\text { insulin treatment }\end{array}$ & & $\begin{array}{c}\text { treatment of mild and } \\
\text { moderate DKA with SC } \\
\text { insulin lispro is equally } \\
\text { effective and safe in } \\
\text { comparison with IV regular } \\
\text { insulin }\end{array}$ & 11 \\
\hline $\begin{array}{l}\text { Umpierrez } \\
\text { et al. }\end{array}$ & RCT & USA & 40 & $\begin{array}{l}\text { to compare the efficacy } \\
\text { and safety of } \\
\text { subcutaneous insulin } \\
\text { lispro with that of low- } \\
\text { dose continuous } \\
\text { intravenous regular } \\
\text { insulin in the treatment } \\
\text { of patients with } \\
\text { uncomplicated diabetic } \\
\text { ketoacidosis }\end{array}$ & & $\begin{array}{l}\text { treatment of adult patients } \\
\text { who have uncomplicated } \\
\text { diabetic ketoacidosis with } \\
\text { subcutaneous lispro every } \\
\text { hour in a non-intensive } \\
\text { care setting may be safe } \\
\text { and more cost-effective } \\
\text { than treatment with } \\
\text { intravenous regular insulin } \\
\text { in the intensive care unit }\end{array}$ & 12 \\
\hline
\end{tabular}


Table (2): A comparison among the included studies regarding the approach and the outcomes.

\begin{tabular}{|c|c|c|c|c|c|c|c|c|}
\hline Study & \multicolumn{2}{|c|}{$\begin{array}{c}\text { Umpierrez et al. } \\
(2004 a) \\
\text { "aspart" }\end{array}$} & \multicolumn{2}{|c|}{$\begin{array}{l}\text { Manna et al. } \\
\qquad(2005)\end{array}$} & \multicolumn{2}{|c|}{$\begin{array}{l}\text { H.O. Ersoz et al. } \\
(2006)\end{array}$} & \multicolumn{2}{|c|}{$\begin{array}{c}\text { Umpierrez et al. } \\
\text { (2004b) } \\
\text { "lispro" }\end{array}$} \\
\hline Patients number & \multicolumn{2}{|c|}{45} & \multicolumn{2}{|c|}{60} & \multicolumn{2}{|c|}{20} & \multicolumn{2}{|c|}{40} \\
\hline Approach type & Aspart Q2h & IV insulin & Lispro Q1h & IV insulin & $\begin{array}{l}\text { Lispro } \\
\text { Q1h }\end{array}$ & IV insulin & Lispro Q1h & $\begin{array}{c}\mathrm{IV} \\
\text { insulin }\end{array}$ \\
\hline Patients number & 15 & 15 & 30 & 30 & 10 & 10 & 20 & 20 \\
\hline Age (years) mean & 38 & 40 & 11.3 & 12.1 & 38.7 & 48.8 & 37 & 39 \\
\hline Glucose (mmol) & 42 & 40 & 24.6 & 24.6 & 28.4 & 30.8 & 37.4 & 33.9 \\
\hline Ward & $\begin{array}{l}\text { General } \\
\text { ward }\end{array}$ & ICU & \multicolumn{2}{|c|}{ Not specified (ED and ICU) } & \multicolumn{2}{|c|}{ Not specified } & \multicolumn{2}{|c|}{ Not specified } \\
\hline $\begin{array}{c}\text { Time needed until } \\
\text { Hyperglycemia } \\
\text { Resolution }\end{array}$ & $6.1 \mathrm{~h}$ & $7.1 \mathrm{~h}$ & $\begin{array}{c}\text { Rate }= \\
-2.9 \\
\mathrm{mmol} / \mathrm{L} / \mathrm{h} \\
\end{array}$ & $\begin{array}{c}\text { Rate }= \\
-2.6 \\
\mathrm{mmol} / \mathrm{L} / \mathrm{h} \\
\end{array}$ & $9.4 \mathrm{~h}$ & $12.7 \mathrm{~h}$ & $7 \mathrm{~h}$ & $7 \mathrm{~h}$ \\
\hline $\begin{array}{c}\text { Time needed until } \\
\text { DKA Resolution } \\
\text { (hours) }\end{array}$ & 10.7 & 11 & 12 & 6 & 14.8 & 13.2 & 10 & 11 \\
\hline $\begin{array}{l}\text { Length of hospital } \\
\text { stay (days) }\end{array}$ & 3.9 & 4.5 & \multicolumn{2}{|c|}{ Not mentioned } & \multicolumn{2}{|c|}{ Not mentioned } & 4 & 4 \\
\hline
\end{tabular}

\section{DKA management:}

The approach to any DKA in any patient start obviously with $\mathrm{ABC}$ approach ${ }^{(15)}$. Then, reaching the diagnosis as early as possible is important in order to act rapidly and prevent the condition from deteriorating to severer level. DKA must be detected quickly by using tests like random blood sugar measuring for hyperglycemia, venous blood gases test for acidosis, and urine dipstick test for ketonuria ${ }^{(15)}$. After diagnosing, fluid therapy must be started immediately by infusion of normal saline $0.9 \% \mathrm{NaCl}$ with $20 \mathrm{ml} / \mathrm{kg} / \mathrm{h}$ rate for 2 hours ${ }^{(10)}$. Due to the volume depletion that is associated with DKA pathophysiology, hypokalemia mostly occur and it should be suspected and avoided by adding KCL to the fluid therapy with $20 \mathrm{mEq}$ per liter ${ }^{(10)}$. For the insulin therapy, it should be started after starting the fluid replacement by giving IV bolus $0.1 \mathrm{IU} / \mathrm{kg}$ followed by continuous insulin infusion with rate of 0.1 unit per $\mathrm{kg}$ per hour ${ }^{(9-12)}$. In our study, we included other insulin therapy than continuous intravenous infusion of insulin protocols for the treatment of DKA such as the subcutaneous insulin. Regarding the subcutaneous injections of insulin if decided, it should be started by subcutaneous lispro every hour with initial dose subcutaneously at rate of 0.3 unit per $\mathrm{kg}$ of body weight, followed by subcutaneous lispro insulin at 0.1 unit per kg every 1 hour ${ }^{(11,12)}$. Other studies suggested the use of another insulin analogues such as aspart. It is done by injecting an initial dose of SC 0.3 units per $\mathrm{kg}$ of aspart insulin followed by 0.2 unit per $\mathrm{kg}$ an hour later, then, 0.2 per $\mathrm{kg}$ unit every 1 or 2 hours ${ }^{(9)}$.
These are the main parts of the approach to a patient with DKA mentioned briefly.

\section{DISCUSSION}

DKA is a life-threatening condition that can be described as a state of extreme low level of insulin. It is the most common hyperglycemic emergency in patients with type 1 and type 2 diabetes ${ }^{(7)}$. The decrease in the level of insulin is opposed by increased level of catabolic and stress hormones like glucagon, catecholamines, and cortisol. This will lead to significant hyperglycemia which will make the fatty cells release free fatty acids. Then, it will be followed by ketone bodies formation by the liver resulting in hormonal imbalance. The body will try to counter the hyperglycaemia, ketonaemia and acidaemia that happened by progressive volume depletion. It will excrete the glucose, and ketones through the urine. This will be accompanied by loss of potassium and phosphorus as well. The complications of this pathophysiology will be tissue hypoxia, hyperviscosity, arrhythmia, and decreased blood flow to target organs like the brain ${ }^{(14)}$. Therefore, DKA needs rapid correct intervention, starting from administration of exogenous insulin to correct the extreme high blood glucose and fluid replacement to the electrolyte imbalance correction.

American diabetes association released criteria about DKA classification whether the presented condition is mild, moderate, and severe or it reached the complication level of Hyperglycemic Hyperosmolar State that may cause 
brain edema and brain damage ${ }^{(14)}$. In this study, we will discuss if mild to moderate uncomplicated DKA cases can be treated with less aggressive treatment and more economical intervention.

In the past, physicians favored the infusion of insulin to be administered intravenously in order to achieve the rapid effect ${ }^{(11)}$. Recently new insulin analogues like aspart and lispro have been released. Although they are administered subcutaneously, they have rapid effect that may take only couple of minutes to start. So, in the present study, we reviewed 4 RCTs that included 165 adult and pediatric patients collectively from USA, Turkey and Brazil (table 1). They compared between IV insulin and S/C insulin in treating mild to moderate uncomplicated DKA cases regarding the efficacy and the safety. Umpierrez et al. ${ }^{(12)}$ group reported in the study that the use of $\mathrm{S} / \mathrm{C}$ insulin lispro in general wards is as effective and safe as the use of intravenous insulin infusion in intensive care units for mild to moderate DKA cases ${ }^{(12)}$. Lispro use was less costly than the IV insulin. However, the problem was that the use of lispro is supposed to be S/C injection every hour. An injection hourly for not less than 10 hours period most of the time will be hard on the nurses because many health care centers have shortage of nurses and this problem is worldwide ${ }^{(9)}$. So, the same group, later after the lispro study, conducted a trial about the use of aspart insulin S/C compared to the IV insulin infusion ${ }^{(9)}$. The difference here is the participants were randomized into 3 groups, patients receive SC aspart insulin every hour (SC-1h, $\mathrm{n}=15$ ) and every $2 \mathrm{~h}(\mathrm{SC}-2 \mathrm{~h}, \mathrm{n}=15)$, and IV regular insulin $(\mathrm{n}=15)^{(9)}$. Fortunately, they did not find statistical differences in the mean duration of treatment until correction of hyperglycemia or until resolution of ketoacidosis among patients treated with $\mathrm{SC}-1 \mathrm{~h}$ and $\mathrm{SC}-2 \mathrm{~h}$ or with IV insulin, respectively. Also, there was no mortality and no differences in the length of hospital stay, total amount of insulin administration until resolution of hyperglycemia or ketoacidosis, or the number of hypoglycemic events among treatment groups (table 2). They added that treatment of diabetic ketoacidosis in the intensive care unit was associated with 39\% higher hospitalization charges than the treatment with subcutaneous insulin in a non-intensive care setting. Therefore, SC aspart insulin every 2 hours can be the best cost-effective method of treatment of uncomplicated DKA.
Speaking of which, Manna et al. ${ }^{(10)}$ group focused in their paper on simplifying DKA treatment and providing more economical solution in order to achieve the optimal life-saving treatment with less costly interventions ${ }^{(10)}$. Therefore, they compared the efficacy of SC lispro every 2 hours with continuous IV regular insulin in the treatment of pediatric DKA. The conclusion of the study was the same as Umpierrez et $\boldsymbol{a l} .{ }^{(9)}$ paper's conclusion which was the SC aspart represents a cost-effective and technically a simplified procedure than continuous IV regular insulin. These results can help in reducing the amount of effort that should be done by nurses, and preclude intensive care unit admissions resulting in reducing a significant amount of hospitalization charges. Umpierrez et al. ${ }^{(12)}$ group found that the average hospitalization charges per day was $\$ 3981$ $( \pm \$ 1067)$ for patients treated in an intensive care unit compared with $\$ 2682( \pm \$ 636)$ for those treated in a non-intensive care setting ${ }^{(12)}$. This conclusion does not only save the patients from paying more unnecessary money, it also saves for the health centers more staff members, ICU beds and other needed resources for more in need patients. In addition, it can save the patients from the thrombophlebitis that is associated with IV live insertion in the mild cases that do not need IV rehydration. It is also a solution for some of the facilities that do not have infusion pumps outside ED or ICU.

\section{STRENGTHS AND LIMITATIONS}

The number of the studies that we included is relatively small and that is a major limitation to our study because it affected also the sample size (mean=41.25 patients per study). Certainly, a bigger sample size would provide more significant results and less prone to bias data.

We included studies that are similar in their main aim of the study and how they approached the patients.

\section{CONCLUSION}

In mild to moderate uncomplicated DKA cases, SC insulin treatment does not differ from continuous IV insulin infusion regarding the efficacy, the safety, and the mean duration of treatment until correction of hyperglycemia or until resolution of ketoacidosis. SC aspart insulin every 2 hours can be safe and effective as much as SC 
aspart or lispro insulin every 1 hours and as much as IV insulin continuous infusion. This method of treatment needs fewer resources from the health care centers and less time from the health care providers.

\section{REFERENCES}

1. Inzucchi SE (2013): Diagnosis of diabetes. N Engl J Med., 368:193.

2. Sato $\mathrm{K}$, Hayashi $\mathrm{T}$, Harita $\mathrm{N}$ et al. (2009): Combined measurement of fasting plasma glucose and $\mathrm{A} 1 \mathrm{C}$ is effective for the prediction of type 2 diabetes: the Kansai Healthcare Study. Diabetes Care, 32: 644-646

3. Shaw JE, Sicree RA, Zimmet PZ (2010): Global estimates of the prevalence of diabetes for 2010 and 2030. Diabetes Res Clin Pract., 87:414

4. Chan JC, Malik V, Jia W et al. (2009): Diabetes in Asia: epidemiology, risk factors, and pathophysiology. JAMA., 301:2129-40

5. Middleton K, Hing E, Xu J (2007): National Hospital Ambulatory Medical Care Survey: 2005 emergency department summary. Adv Data, 386:1-32.

6. Kitabchi A, Umpierrez GE, Murphy MB et al. (2009): Hyperglycemic Crises in Adult Patients With Diabetes: A Consensus Statement From the American Diabetes Association: Response to Rosival. Diabetes Care, doi:10.2337/dc07-0694.

7. American Diabetes Association (2006): Diagnosis and Classification of Diabetes Mellitus. Diabetes Care, 29:2739-2748.3.

8. Alberti KG (1977): Low-dose insulin in the treatment of diabetic ketoacidosis. Arch Intern Med., 137:1367-1376.

9. Umpierrez GE, Cuervo R, Karabell A et al. (2009): Treatment of Diabetic Ketoacidosis With Subcutaneous Insulin Aspart. Diabetes Care, 27(8): 1873-878.

10. Manna T D, Steinmetz L, Campos Subcutaneous et al. (2005): Use of a FastActing Insulin Analog: An Alternative Treatment for Pediatric Patients with Diabetic Ketoacidosis. Diabetes Care, 28(8): 1856-861.
11. Ersöz HÖ, Ukinc K, Köse $M$ et al. (2005): Subcutaneous Lispro and Intravenous Regular Insulin Treatments Are Equally Effective and Safe for the Treatment of Mild and Moderate Diabetic Ketoacidosis in Adult Patients. International Journal of Clinical Practice, 60(4): 429-433.

12. Umpierrez GE, Latif $K$, Stoever J et al. (2004): Efficacy of Subcutaneous Insulin Lispro versus Continuous Intravenous Regular Insulin for the Treatment of Patients with Diabetic Ketoacidosis. The American Journal of Medicine, 117(5):291296.

13. Vincent $M$, Nobécourt $\mathbf{E}$ (2013): Treatment of Diabetic Ketoacidosis with Subcutaneous Insulin Lispro: A Review of the Current Evidence from Clinical Studies. Diabetes \& Metabolism, 39(4):299-305.

14. Andrade-Castellanos CA, Colunga-Lozano LE, Delgado-Figueroa N (2014): Subcutaneous Rapid-acting Insulin Analogues for Diabetic Ketoacidosis. Cochrane Database of Systematic Reviews. doi:10.1002/14651858.cd011281.

15. Murray L, Wilkinson I, Baldwin A, Wallin $\mathbf{E}$ (2014): Oxford Handbook of Clinical Medicine 9th Edition. Oxford Medicine Online. doi:10.1093/med/9780199609628.001.0001. 